\title{
Erratum to: Tanshinone IIA Ameliorates Trinitrobenzene Sulfonic Acid (TNBS)-Induced Murine Colitis
}

\author{
Aiping Bai · Nonghua Lu • Yuan Guo • \\ Xianmin Fan
}

Published online: 21 January 2012

(C) Springer Science+Business Media, LLC 2012

\section{Erratum to: Dig Dis Sci (2008) 53:421-428 \\ DOI 10.1007/s10620-007-9863-8}

We had erroneously referred to the test compound used in this study [1] as "Tanshinone IIA" instead of the correct name "tanshinone." Corrected text is given below.

\section{Treatment of Tanshinone}

Danshen solution was purchased from No. 9 Pharmaceutical and Biological Co. (Shanghai, China). One ml Danshen solution containing about $1.5 \mathrm{~g}$ tanshinone was dissolved in distilled water and diluted to a final concen- tration of $200 \mathrm{mg} / \mathrm{ml}$. About 10 or $20 \mathrm{mg}$ tanshinone was administered orally to mice $4 \mathrm{~h}$ before the induction of colitis, and repeated daily until the mice were sacrificed.

The original conclusions are not changed with correction of this error.

\section{Reference}

1. Bai A, Lu N, Guo Y, Fan X. Tanshinone IIA ameliorates trinitrobenzene sulfonic acid (TNBS)-induced murine colitis. Dig Dis Sci. 2008;53:421-428.

The online version of the original article can be found under doi:10.1007/s10620-007-9863-8.

A. Bai $(\bowtie) \cdot$ N. Lu

Department of Gastroenterology, The First Affiliated Hospital,

Nanchang University, Nanchang City 330006, China

e-mail: baiap@163.com

Y. Guo

Department of Pharmacy, The First Affiliated Hospital,

Nanchang University, Nanchang City 330006, China

X. Fan

Department of Medicine, The Affiliated Hospital,

Luzhou Medical College, Luzhou City 646000, China 